\title{
PEDAGOGIA DO TEATRO: UMA EXPERIÊNCIA DE ENSINO- APRENDIZAGEM NA SALA DE AULA
}

Leide Rosane Alcântara

Recebido em 30/06/2017

Aprovado em 04/09/2017 
O presente trabalho traz uma análise reflexiva a respeito do ensino de teatro na escola, defendendo essa prática pela tríplice abordagem que engloba os fazeres do corpo, as tecnologias e o corpo teórico metodológico do teatro. Dessa forma, isto proporciona uma troca de experiência entre professor e estudante; oferece uma experiência artística em aula de teatro mais completa; estimula os estudantes a desenvolverem seu potencial individual e permite que o processo seja enriquecido por meio da contribuição direta de cada indivíduo envolvido na experiência em sala de aula. Trata-se de atuar com uma visão crítica do que é positivo para o processo, pois mesmo com as inúmeras dificuldades encontradas para se efetivar o ensino de teatro na escola, defendo que o ensino das artes cênicas, como uma habilitação necessária pela sua importância e relevância como proposta pedagógica, possibilita ao estudante a reflexão crítica e o pensar com o corpo e com a voz. Além disso, considero as inúmeras possibilidades, oportunizadas pelo teatro na escola, de ler a realidade do mundo por meio deste, enriquecendo assim o processo ensino-aprendizagem atual e contribuindo para a formação das novas gerações.

Palavras-Chave: Teatro. Educação. Experiência.

\section{Diálogos INICIAIS}

$\mathrm{O}$ teatro, como importante forma de expressão artística milenar, sempre esteve presente, acompanhando os seres humanos em sua coletividade. Nesse sentido, "[...] a arte, em todas as suas formas (...) era a atividade social por excellence, comum a todos e elevando todos os homens acima da natureza, do mundo animal" (FISCHER, 1987, p. 47).

A arte teatral está em palcos profissionais ou amadores, em prédios estruturados e denominados casas de espetáculos, e a partir desses locais de intervenção, nas ruas, praças e feiras, evoluindo e tornando-se cada vez mais atuante, alcançando espaço em lugares diferenciados, como nas igrejas, nos presídios e em outros espaços sociais.

Com essa trajetória de amplitude e penetração, a arte teatral foi conquistando espaço também em instituições de ensino público e privado, fazendo parte e sendo fundamental, ao longo dos anos, do processo de ensino-aprendizagem. A exemplo disso, tem-se o Festival de Teatro Estudantil do NTU (Núcleo de Teatro Universitário), no Teatro Lima Penante, pertencente à Universidade Federal da Paraíba, que, existindo há vinte e oito anos ininterruptos, envolve estudantes e tem difundido o fazer teatral nas escolas públicas e privadas. 
Este texto discute a prática teatral a partir de um olhar que considera o envolvimento mútuo entre estudantes em sala de aula, bem como a realidade em que estão inseridos de forma direta e a grande diversidade de saberes e ampla abordagem que o teatro possibilita.

De todas as aulas que a disciplina Fundamentos Teóricos da Arte na Educação ofereceu, dentro do Curso de Mestrado Profissional em Artes, a que me causou mais impacto ao assistir a vídeo-aulas, foi a aula da área específica de teatro. Chamou-me muito a atenção quando o professor facilitador iniciou a aula fazendo uso de uma contação de história e expressando de forma clara que o exemplo dado era verídico e tão próximo de seu convívio, de sua realidade - envolvendo de forma direta os seus filhos; filhos de um ator, arte educador, encenador, ou seja, de um profissional altamente envolvido com o teatro, que talvez espere que seus herdeiros desenvolvam prazer e satisfação com o brincar do fazer teatral.

Segundo Koudela (2006, p. 78) “[...] o teatro, enquanto proposta de educação, trabalha com o potencial que todas as pessoas possuem, transformando esse recurso natural em um processo consciente". Em vez disso, porém, quando, de repente, as pessoas se depararam com o ensino dessa arte de maneira formal em sala de aula, esse sentimento, que antes era representado por prazer e diversão, passou a ser sentido de forma inversa, sendo que não restou nem a vontade de permanecer espectador.

Tudo isso seria fruto de uma experiência que não foi bem trabalhada, de uma pedagogia teatral mal sucedida. Muitas vezes não se leva em conta as individualidades e características marcantes de cada um, principalmente de acordo com a faixa etária dos estudantes, e isso influencia diretamente no processo de ensino-aprendizagem, tendo em vista que cada idade tem suas necessidades e pontos marcantes, que são modificados e transformados de acordo com cada fase das faixas etárias, cada etapa do crescimento biopsicossocial do ser humano.

Minha inquietação em relação a esse tema, tão pouco pensado e discutido em meio a uma rotina diária e "corrida" em nosso meio profissional escolar, veio a partir da observação de minha própria experiência. Durante minha vida estudantil, no período que corresponde ao ensino fundamental II e Médio, na rede pública de ensino, na cidade de João Pessoa, Paraíba, fui agraciada com excelentes arte educadores. Minha trajetória nessa fase foi marcada por profissionais maravilhosos, professores que, mesmo atuando na rede pública de ensino, com suas limitações materiais e financeiras, dificuldades operacionais e frustrações por não poderem dar o melhor de si para aqueles estudantes, eram comprometidos com o ensino de qualidade do teatro e da dança.

Esses professores souberam transmitir isso com excelência, gerando em mim, de forma satisfatória, um misto de conhecimento e prazer. 
Segundo Spolin (2005), "experimentar é penetrar no ambiente, é envolverse total e organicamente com ele" (SPOLIN, 2005, p. 3), e era assim que me sentia em meio às maravilhosas aulas de teatro da época de estudante, totalmente envolvida pelo mundo cênico que me era apresentado. Nesse sentido, para Cananéa "por sermos sujeitos históricos, os momentos que vivemos ajudaram a nos formar como pessoa. O que somos hoje tem grande influência em nossas escolhas, tanto pessoais quanto profissionais" (CANANÉA, 2016, p. 35).

Toda essa experiência contribuiu de forma grandiosa para meu crescimento pessoal e teve fundamental importância em minha escolha de formação profissional (como arte educadora). A sala de aula, para mim, hoje, representa um desafio de responsabilidade e comprometimento na continuação por plantar essa semente que tem germinado, motivando-me a desejar que outros estudantes possam desfrutar do prazer que a arte teatral proporciona em sua prática e fortalecendo a construção de possibilidades de cidadania por meio dessas práticas.

Ainda no Mestrado em Artes, com a disciplina A experiência artística e a prática do ensino de artes na escola (abordagens metodológicas) tive a oportunidade de pensar mais e buscar aprimoramento sobre as práticas, as abordagens e, acima de tudo, sobre a compreensão de como tem sido o ensino de teatro. Sendo assim, qual o caminho? De que forma o ensino de teatro tem chegado à sala de aula? Quais metodologias produzem êxito? Quais metodologias frustram os estudantes? Como essa experiência artística tem acontecido na prática do ensino de Artes?

Foi um momento reflexão sobre teoria e prática, sobre a atividade docente diária no âmbito escolar e social, de reconhecimento sobre o fato de que "a arte tem uma contribuição única a dar para a experiência e a cultura humana, diferenciando-a de outros campos de estudo" (KOUDELA, 2006, p. 18), e isso representa um importante legado para a humanidade. A pedagogia teatral em si representa um grande desafio, uma responsabilidade que é colocada nas mãos do arte educador, de desenvolver um trabalho focado e comprometido com a visão de que "[...] a arte teatral pode e precisa ser acessível a todos" (DESGRANGES, 2011, p. 36).

A comunidade estudantil de hoje precisa vivenciar o teatro dessa forma, com envolvimento e prazer. Assim, este texto é escrito com a motivação de pensar o tema, na perspectiva do aprimoramento da prática docente no ensino de teatro em sala de aula, para que, assim, seja rompido esse círculo vicioso de se "aleijar" pessoas através de fórmulas de ensino engessadas e que em muitas vezes promovem rejeição em vez de atração pelo processo de ensino-aprendizagem, que envolve diretamente professor e estudante.

Esse processo, diariamente, se mostra desafiador, em meio a todas 
as dificuldades estruturais e sociais que o ensino das Artes apresenta, que vão desde a falta de espaço físico, até o preconceito que a arte sofre entre a comunidade escolar em geral. No âmbito educacional, no ensino fundamental e médio, podemos presenciar isso na prática diária e, assim, "constata-se que o ensino das artes, na educação escolar brasileira, segue concebido por muitos professores, funcionários de escolas, pais de estudantes e os próprios estudantes como supérfluo, caracterizado quase sempre como lazer, recreação" (JAPIASSU, 2001, p. 23).

Essa visão coloca o ensino das Artes de maneira descomprometida e desqualificada, tornando-se esta uma disciplina lecionada por qualquer pessoa, sem necessariamente a exigência de uma qualificação profissional direcionada. Esse é um desafio que se tenta mudar ao longo de décadas: quebrar a ideia de arte apenas como recreação, ou enquanto aquele momento de os estudantes descansarem das disciplinas ditas "sérias".

Nesse sentido, partir em busca de "[...] um teatro fortemente marcado por sua vontade educacional” (DESGRANGES, 2011, p. 51) é a perspectiva defendida a partir deste texto, em que se busca refletir sobre as práticas do ensino teatral, com base numa visão geral da pedagogia do teatro, enquanto experiência prazerosa e com envolvimento social. Nessa direção, procura-se, a partir de análises feitas sobre o tema, compreender uma prática docente mais completa, baseada no ensino de teatro direcionado pela tríplice abordagem, que mais à frente será abordada.

\section{Navegando na Discussão do Tema}

7 econhece-se a representação como uma necessidade que "[..] desde a infância os homens tem, na sua natureza, uma tendência a - representar e uma tendência a sentir prazer com as representações" (GUENOUN, 2004, p. 18). Com o passar dos anos e o crescimento do ser humano, vai sendo abandonada essa natureza de sentir prazer com as representações, se perdendo no tempo, pelos padrões de uma sociedade engessada, caótica e impessoal, em que as necessidades e o prazer do indivíduo sempre ficam em segundo plano, pois o primeiro é ocupado por interesses mercantilistas de nosso sistema capitalista. Carlos Brandão em seu texto A Educação Como Cultura explica:

Vivemos a experiência de uma cultura que, se de um lado acelera os mecanismos sociais e pedagógicos da concorrência e da competição, a ponto de aos poucos transformar a própria educação em uma espera ansiosa de um exame para acesso a uma universidade inimaginável, de outro lado transforma competidores em assistentes ou praticantes de 
tarefas uniformes e fáceis, dentro de um mundo onde todas as coisas são pré-construídas, todas as questões antecipadas e todas as dificuldades présolucionadas (BRANDÃO, 1985, p. 122).

Essa ainda é uma realidade da educação. Muitas vezes nos deparamos com a corrida da vida em um círculo vicioso, de competir, concorrer, ser o melhor, ser o número "um". Crianças, desde muito cedo, são acostumadas a esse padrão, de forma que muitas vezes lhes é roubada a chance de vivenciar, de ter uma experiência e ir aos poucos aprendendo com essas experiências vividas. Alguns estudantes não são preparados para a vida e, muitas vezes, sem levar em conta princípios e valores humanos, são direcionados, como o lançar de uma flecha, para exames seletivos, para ingressar em uma carreira, sem apresentar segurança de escolha e muitas vezes influenciados por terceiros.

Além disso, estudantes são preparados, na maioria das vezes, a partir de uma educação muito técnica, em que não é dada ao indivíduo a oportunidade de criar. É como se não fossem um seres pensantes, sempre rodeados de práticas laborais uniformes, que muitas vezes estão a serviço de um mercado de consumo, em um mundo onde as respostas já estão prontas e onde tudo parece ser "descartável", inclusive os seres humanos. Em um mundo onde o pensar, o ser crítico e o criar já não têm valor.

Associada a todos esses fatores, ainda nos deparamos com uma pedagogia do teatro ultrapassada, que ainda podemos observar na maioria das aulas de teatro, em processos de obrigatoriedade do fazer teatral, nos quais o ensino é trabalhado pela perspectiva de um único lado, o de ser ator, o da necessidade de se estar no palco.

Com base na necessidade que acompanha o homem desde sua infância, com a representação e o prazer de ver as representações, o teatro se consolida como uma atividade de mão dupla, em que estão presentes duas peças chave, a existência do ator e a do espectador, ambos tendo seu imenso e insubstituível valor.

O teatro, segundo Japiassu "[...] passou a ser reconhecido como forma de conhecimento capaz de mobilizar, coordenando as dimensões sensóriomotora, simbólica, afetiva e cognitiva da realidade humana" (JAPIASSU, 2001, p. 28). Dessa forma, questiona-se: por que mesmo com esse reconhecimento que o teatro vem adquirindo de forma teórica, podemos constatar, na prática, uma desmobilização?

Muito se tem conquistado com relação ao ensino de teatro na educação, por meio de leis e editais. Debates em cursos, seminários, graduações e pósgraduações trabalham para uma efetivação qualitativa da atividade nas instituições de ensino, porém, infelizmente, na prática diária, essa gama de esforços parece insuficiente, tendo em vista o alto número de escolas públicas e privadas, nos âmbitos municipal, estadual e até mesmo nacional, que ainda 
se encontram órfãs e desprivilegiadas pela falta do ensino teatral, sendo essa uma triste realidade. Trata-se de um quadro de escolas em que o teatro não passa de utopia, e onde seus estudantes são, ao longo dos anos, podados da oportunidade de experimentar essa expressão artística importantíssima e tão significativa para o indivíduo e para a sociedade em geral.

Pessoas estão perdendo o interesse por essa arte e até mesmo deixando de desenvolver todo o crescimento pessoal que o teatro pode oferecer, por se frustrarem com o ensino, ainda que hoje esteja sendo oferecido por profissionais licenciados em áreas especificas - o que foi uma grande evolução com a aprovação da LDB-Lei de Diretrizes e Bases da Educação Nacional, Lei no 9.394 de 1996, em que o ensino das artes passa a ser obrigatório e traz consigo uma defesa do ensino das artes cênicas na escola fundamental como uma necessidade.

Sendo assim, mesmo sem uma boa efetivação prática, reconhecese hoje o ensino do teatro na escola como algo que vai para além do entretenimento, como uma importante forma de comunicação e expressão. Ainda assim, após a aprovação da Lei, vamos encontrar uma grande parte do corpo docente em escolas públicas e privadas lecionando como "leigos" no processo pedagógico do teatro, além de encontrarmos docentes de disciplinas como história, geografia, ciência e inglês, complementando sua carga horária de trabalho lecionando a disciplina de Arte, o que de forma inevitável gera uma lacuna na formação do estudante.

Contemplação é algo ativo e proativo, ou deveria ser. Sobre isso, Desgranges afirma:

O primeiro aspecto pedagógico presente na experiência com a arte é a atitude proposta ao contemplador, ou seja, o fator artístico solicita que o indivíduo formule interpretações próprias acerca das provocações estéticas feitas pelo autor, elaborando um ato que é também autoral (DESGRANGES, 2011, p. 28).

Desgranges (2011) traz a importância do espectador para o teatro de forma ativa, participativa e a divide em dois momentos: "em um primeiro momento o espectador se aproxima da obra, vivenciando-a e, em um segundo momento se afasta dela para refletir sobre ela, compreendendo-a" (DESGRANGES, 2011, p. 29).

Em uma experiência artística, tudo tem um valor, uma função determinada e com importância específica. Sendo assim,

Quanto mais interagimos, comunicamos, fazemos uso das linguagens, sejam elas artísticas ou não, mais somos uma troca com o outro. Mais mista torna-se nossa individualidade. Mais coletivas ficam nossas características. Que nos percebamos então, todos nós, compostos por fragmentos de uma unicidade (OLIVEIRA, 2012b, p. 27). 
Para o teatro, essa unicidade é fundamental. Ator e espectador estão ligados um ao outro, e sem algum deles, não há teatro. O teatro é isso, essa junção interativa, essa troca de querer ver e querer ser visto, entendendo que a atuação do ator interfere na plateia e que a atuação da plateia, seja ela ativa ou não, interfere diretamente no trabalho do ator. Ambos interagem, se comunicam através de uma linguagem que é própria do mundo cênico; misturam-se, se envolvem, cada um com suas individualidades, e dessa troca ator-espectador, espectador-ator, acontece a magia envolvente do teatro.

Se essa visão fizesse parte de nossa prática diária no ensino de Arte, o trabalho de formação e conscientização de plateia e o trabalho junto aos estudantes com o ensino de teatro na sala de aula seria visto com outros olhos, o estudante passaria a ser entendido como um agente participante do processo de ensino-aprendizagem.

Talvez essa mudança de ponto de vista e de atitude, frente ao ensino, trouxesse um pouco mais de equilíbrio para algo que podemos observar como uma disparidade entre a grande quantidade de pessoas que buscam fazer cursos de teatro fora das salas de aulas e, por outro lado, o pequeno número de espectadores que buscam assistir a arte teatral. Podemos observar que não deve existir a obrigatoriedade de se subir ao palco, já que um estudante pode aprender muitas coisas em diversas áreas que compõem esse universo tão abrangente do teatro, a partir de várias abordagens, inclusive sendo espectador, pois “[...] a participação do espectador, precisa ser compreendida como um ato criativo, produtivo e autoral" (DESGRANGES, 2011, p. 37).

O teatro atua com forte influência na construção de valores e princípios sociais e é de grande importância. Como defende Cartaxo (2001): "a atividade lúdica, surge pedagogicamente, como à base estruturadora da organização do grupo, desenvolvendo aspectos de solidariedade, respeito, compreensão, democracia, liderança e liberdade" (CARTAXO, 2001, p. 43), considerandose o grande potencial que o teatro oferece ao processo ensino-aprendizagem.

Para que essa gama de qualidades seja verdade e atue de maneira eficaz, é preciso ter um olhar voltado para uma abordagem tríplice, como proposta no teatro pedagógico, englobando os fazeres do corpo (a interação entre o corpo que está fazendo e o que está assistindo, em seu estado intencionalmente alterado e com uma consciência clara e objetiva dessa troca experiencial), das tecnologias (cenografia, figurino, maquiagem, iluminação, cenotécnica, audiovisual) e do corpo teórico metodológico (a história, crítica, teoria, pedagogia, registros), proporcionando assim uma troca de experiência entre professor e estudante e oferecendo uma experiência artística mais completa na aula de teatro.

Para que essa experiência aconteça acompanhada do que Dewey (2010, p. 84) chama de "experiência estética", ou seja, uma percepção prazerosa, o 
estudante em sala não pode ser visto como uma esponja, sempre pronto para absorver tudo aquilo que lhe é oferecido, sem levar em consideração aquilo que lhe traz satisfação.

O educando já traz consigo uma bagagem de conhecimentos e experiências das mais diversas possíveis, construídas a partir de vivências, influências, e de acordo com o círculo familiar e de amigos em que se insere. Segundo Freire, "[...] a verdadeira educação é um ato dinâmico e permanente de conhecimento centrado na descoberta, análise e transformação da realidade pelos que a vivem" (FREIRE, 1983, p. 75). Dessa forma, o processo ensino-aprendizagem se apresenta muito rico e dinâmico se for uma constante troca de saberes, em que educador e educando estão juntos, ensinam juntos, aprendem juntos, transformam-se individual e coletivamente.

Na prática docente diária, em sala de aula, nos deparamos com essa realidade estudantil a cada instante. Sempre podemos perceber as preferências e aptidões de cada estudante, sendo que alguns se envolvem diretamente em atividades práticas, enquanto outros se animam e se dedicam mais a atividades técnicas ou teóricas.

Nesse sentido, cabe ao professor ter uma visão crítica para atuar a partir de uma abordagem ampla e diversa, objetivando atrair de forma envolvente e satisfatória os estudantes, respeitando as limitações e a faixa etária de cada um, proporcionando a eles uma aprendizagem eficaz no extenso âmbito das artes cênicas, oportunizando-lhes o desenvolvimento da reflexão crítica e do pensar com o corpo, com a voz e das inúmeras possibilidades de ler a realidade do mundo por meio do teatro. Nessa perspectiva, segundo Cananéa (2016), busca-se

Fortalecer em seus protagonistas a descoberta e o exercício de suas potencialidades e talentos artístico-culturais, sem abdicar de ajudálos também a identificar e a superar os próprios limites, pelo exercício contínuo da autocrítica. Promover o uso das múltiplas linguagens, de modo a não tornar seus participantes reféns do uso exclusivo da oralidade (CANANÉA, 2016, p. 170).

Todos podem aprender teatro a partir da abordagem que lhes for mais confortável, mais prazerosa. Assim é gerado o interesse pela aprendizagem da atividade teatral, pela livre e espontânea vontade de aprender de forma apreciativa e voluntária, e não pela obrigação de se cumprir um programa de aulas.

É importante fazer-se uso do saber compartilhado. Dessa forma, o professor não é visto como detentor de todo o conhecimento, mas atua diretamente como um facilitador do processo de ensino-aprendizagem, estimulando seus estudantes no desenvolvimento de seus potenciais individuais e permitindo que o processo seja enriquecido por meio da 
contribuição direta de cada indivíduo envolvido na vivência em sala de aula.

Devemos atuar com a visão crítica do que é positivo para o processo, de maneira a promover um crescimento, através da atração do estudante pelas práticas teatrais, mantendo-o envolvido por interesse próprio, por satisfação pessoal. Nesse sentido, "[...] agregar aspectos positivos que promovam melhoria no processo de ensino-aprendizagem é o desejo de todo educador" (OLIVEIRA, 2012c, p. 14).

Reconhecemos que cada pessoa já tem um acúmulo de experiências, conhecimentos e vivências que influenciam diretamente sua percepção, e isso é que Dewey (2010) chama de "carga direta". Importa também o fato de que o estudante que reage na produção do objeto experimentado é um sujeito cujos modos de "[...] observação, desejo e emoção são moldados por experiências anteriores” (DEWEY, 2010, p. 240). O estudante carrega em si as experiências passadas não por uma memória consciente, mas pela carga direta.

\section{Considerações Finais}

$\mathrm{E}$

chegado o momento de nossas inquietações - em relação às mudanças necessárias no ensino de teatro na escola - saírem do papel e dos debates orais, bem como das mentes dos docentes para serem quebrados paradigmas, para que essa mudança do pensar derrube barreiras e conquiste uma prática diferente, que atenda a uma necessidade que urge por modificações.

É preciso tornar mais abrangente e atuante o fazer teatral, saindose única e exclusivamente dos palcos e acompanhando as infinitas possibilidades que o teatro oferece por fazer parte das artes cênicas, sendo essa uma área tão expressiva e inclusiva. Assim como a pedagogia do teatro foi ao longo do tempo se transformando, sendo moldada de acordo com as necessidades e realidades de cada momento histórico, "[...] é necessário essa inquietação e provocação se fazer presente no âmbito da instituição escolar" (DESGRANGES, 2011, p. 15).

A escola, de maneira geral, incluindo estudantes, arte educadores e demais profissionais, precisa colocar em prática um olhar mais profundo para essa pedagogia, passando a enxergar o fazer teatral no contexto estudantil como um todo, entendendo suas particularidades, assim como os aspectos que facilitam e dificultam, na prática diária, a expansão do saber teatral em contextos diversos, e proporcionando assim uma prática educacional cênica transformadora, edificante e completa. Indo nessa direção, Fischer (1987) afirma: 
A arte é o meio indispensável para essa união do indivíduo com o todo; reflete a infinita capacidade humana para a associação, para a circulação de experiências e ideias. Essa definição da arte como o meio de tornarse um com o todo da realidade, como o caminho do indivíduo para a plenitude (FISCHER, 1987, p. 13).

Ousemos e modifiquemos nossas práticas teatrais em sala de aula, para que a experiência artística possa ser vivenciada como uma experiência estética e de amplo aproveitamento para todos os envolvidos no fazer educacional, considerando-se que

A arte pode elevar o homem de um estado de fragmentação a um estado de ser íntegro e total. A arte capacita o homem para compreender a realidade e o ajuda não só a suportá-la como a transformá-la, aumentando-lhe a determinação de torná-la mais humana e mais hospitaleira para a humanidade. A arte, ela própria, é uma realidade social (FISCHER,1987, p. 57).

De acordo com Oliveira, “[...] na escola temos o dever de ensinar e a missão de aprender, que façamos de forma significativa, criativa e interessante aos estudantes. Que façamos Arte" (OLIVEIRA, 2017, p. 59). Ao mesmo tempo que reafirmamos a importância do ensino do teatro na sala de aula, registramos o retrocesso que o governo federal tenta impor à educação brasileira, com a reforma do ensino médio - Lei nº 13.415/2017 - retirando da matriz curricular a possibilidade de se pensar de forma autônoma e crítica, pois tornar não obrigatório o ensino de história é querer matar nossa memória, nossa arte, enfim, nossa historicidade.

Também nessa Lei houve a flexibilização da necessidade de se ter licenciatura para lecionar, introduzindo o notório saber para todas as disciplinas, legalizando o que de certa forma existe em alguns lugares, onde professores de outras áreas complementam sua carga horária lecionando artes e outras disciplinas, sem ter formação para tal.

O ensino de Arte e notadamente o teatro como processo de ensinoaprendizagem sofrem um profundo golpe e esse retrocesso pode nos levar de volta à idade do obscurantismo. A Arte é necessária, então, façamos Arte. 


\section{REFEREANCIAS}

BRANDÃO, Carlos. A educação como cultura. São Paulo: Brasiliense, 1985.

CANANÉA, Fernando A. Abath L. C. Educação popular e identidade cultural. João Pessoa: Imprell Gráfica Editora, 2016.

CARTAXO, Carlos. $\mathbf{O}$ ensino das artes cênicas na escola fundamental e média. João Pessoa: UFPB/BC, 2001.

DESGRANGES, Flávio. Pedagogia do teatro: provocação e dialogismo. 2.ed. São Paulo: Crucite, 2011.

DEWEY, John. Arte como experiência. Trad. Vera Ribeiro. São Paulo: Martins Fontes, 2010.

FISCHER, Ernest. A necessidade da arte. Tradução Anna Bostock. Rio de Janeiro: Editora Guanabara,1987.

FREIRE, Paulo. Educação e mudança. Tradução de Moacir Gadotti e Lilian Lopes Martin. 12. ed. Rio de Janeiro: Paz e Terra, 1983. (Coleção Educação e Comunicação, Vol1).

GUÉNOUN, Denis. O teatro é necessário? São Paulo: Perspectiva, 2004.

JAPIASSU, Ricardo. Metodologia do ensino do teatro. 8. ed. São Paulo: Ed. Papirus, 2001.

KOUDELA, Ingrid. Jogos teatrais. São Paulo: Perspectiva, 2006.

MEC. Parâmetros Curriculares Nacionais - Arte. Ensino Fundamental. Brasília: MEC, 2007.

OLIVEIRA, Ailza de Freitas. O Rio da Nascente à Foz: a escola do PPP à aprendizagem. In:CANANÉA, Fernando Abath (Org.). Educação e suas Interfaces: conversas em torno da educação, da arte e da cultura. João Pessoa, PB: Gráfica e Editora Imprell, 2012b.

Avaliação Técnica e Pedagógica da Tecnologia Educacional E-proinfo: sob o olhar de uma educadora. In: CANANÉA, Fernando Abath (Org.). Trilhas Educacionais. João Pessoa, PB: Gráfica e Editora Imprell, 2012c.

A escola e o combate ao Aedes Aegypti: uma ação ecopedagógica interdisciplinar na disciplina de Artes. In: CANANÉA, Fernando Abath (Org.). Ser Educacional: reflexões pedagógicas. João Pessoa, PB: Gráfica e Editora Imprell, 2017.

SPOLIN, Viola. Improvisação para o teatro. São Paulo: Perspectiva, 2005. 